\title{
Association of TOMM40 and SLC22A4 polymorphisms with ischemic stroke
}

\author{
YUICHIRO YAMASE ${ }^{1}$, HIDEKI HORIBE ${ }^{1}$, CHIKARA UEYAMA ${ }^{1}$, TETSUO FUJIMAKI ${ }^{2}$, MITSUTOSHI OGURI ${ }^{3}$, \\ KIMIHIKO KATO $^{4}$, MASAZUMI ARAI ${ }^{5}$, SACHIRO WATANABE $^{5}$ and YOSHIJI YAMADA ${ }^{6}$ \\ ${ }^{1}$ Department of Cardiovascular Medicine, Gifu Prefectural Tajimi Hospital, Tajimi, Gifu 507-8522; \\ ${ }^{2}$ Department of Cardiovascular Medicine, Inabe General Hospital, Inabe, Mie 511-0428; ${ }^{3}$ Department of Cardiology, \\ Kasugai Municipal Hospital, Kasugai, Aichi 486-8510; ${ }^{4}$ Department of Internal Medicine, Meitoh Hospital, Nagoya, \\ Aichi 465-0025; ${ }^{5}$ Department of Cardiology, Gifu Prefectural General Medical Center, Gifu 500-8717; ${ }^{6}$ Department \\ of Human Functional Genomics, Life Science Research Center, Mie University, Tsu, Mie 514-8507, Japan
}

Received March 24, 2015; Accepted April 3, 2015

DOI: 10.3892/br.2015.457

\begin{abstract}
Recent genome-wide association studies (GWASs) and their meta-analyses have identified various genes and loci underlying the predisposition to ischemic stroke or coronary artery disease in Caucasian populations. Given that ischemic stroke and coronary artery disease may have a shared genetic architecture, certain polymorphisms may confer genetic susceptibility to these two diseases. The aim of the present study was to examine the possible association of ischemic stroke with 29 single-nucleotide polymorphisms (SNPs) previously identified by the meta-analyses of GWASs as susceptibility loci for coronary artery disease. The study population comprised 3,187 Japanese individuals, including 894 subjects with ischemic stroke and 2,293 controls. The genotypes for the 29 SNPs of the 28 genes were determined by a method that combines the polymerase chain reaction and sequence-specific oligonucleotide probes with suspension array technology. Comparisons of the allele frequencies by the $\chi^{2}$ test between subjects with ischemic stroke and controls revealed that $\mathrm{rs} 9319428(\mathrm{G} \rightarrow \mathrm{A})$ of the fms-related tyrosine kinase 1 gene $(\mathrm{P}=0.0471), \mathrm{rs} 2075650(\mathrm{G} \rightarrow \mathrm{A})$ of the translocase of outer mitochondrial membrane 40 homolog gene (TOMM40, $\mathrm{P}=0.0102)$ and $\mathrm{rs} 273909(\mathrm{~T} \rightarrow \mathrm{C})$ of the solute carrier family 22 , member 4 gene $(S L C 22 A 4, \mathrm{P}=0.0097)$ were significantly $(\mathrm{P}<0.05)$ associated with the prevalence of ischemic stroke. Multivariable logistic regression analysis with adjustment for age, gender, body mass index, smoking status and the prevalence of hypertension, diabetes mellitus and dyslipidemia revealed that rs2075650 of TOMM40 $(\mathrm{P}=0.0443$;
\end{abstract}

Correspondence to: Professor Yoshiji Yamada, Department of Human Functional Genomics, Life Science Research Center, Mie University, 1577 Kurima-machiya, Tsu, Mie 514-8507, Japan E-mail: yamada@gene.mie-u.ac.jp

Key words: genetics, polymorphism, genetic epidemiology, ischemic stroke, cerebral infarction recessive model; odds ratio=0.50) and $\mathrm{rs} 273909$ of $S L C 22 A 4$ $(\mathrm{P}=0.0123$; dominant model; odds ratio=0.45) were significantly associated with ischemic stroke with the minor $\mathrm{G}$ and $\mathrm{C}$ allele, respectively, being protective against this condition. TOMM4O and SLC22A4 may thus be susceptibility loci for ischemic stroke in Japanese individuals.

\section{Introduction}

Stroke is a complex multifactorial disorder that is believed to result from an interaction between a person's genetic background and various environmental factors $(1,2)$. It is a common and serious condition, with $\sim 795,000$ individuals having experienced a new or recurrent stroke and $\sim 130,000$ fatalities having occurred from stroke-related causes in the United States in 2010 (3). The prevalence of stroke in the United States is $\sim 6.8$ million. Of all such events, $87 \%$ are ischemic stroke, $10 \%$ are intracerebral hemorrhage and $3 \%$ are subarachnoid hemorrhage (3). Despite recent advances in the treatment for the acute phase of stroke, stroke remains the leading cause of severe disability and the fourth leading cause of mortality, following heart disease, cancer and pulmonary disease in Western countries (3-5). The identification of biomarkers for stroke risk is important for risk prediction and intervention to avert future cerebrovascular events.

Ischemic stroke (particularly atherothrombotic cerebral infarction) and coronary artery disease are atherosclerotic diseases that share various aspects of their underlying pathogenesis, as well as several risk factors, including hypertension, dyslipidemia, diabetes mellitus and smoking. Twin and family studies have demonstrated that ischemic stroke and coronary artery disease are highly heritable $(6,7)$ with evidence of a shared heritability for the two conditions (8). Recent genome-wide association studies (GWASs) and their meta-analyses have identified various genes and loci underlying the predisposition to ischemic stroke $(9-13)$ or coronary artery disease $(14,15)$ mainly in Caucasian populations. Among these genes and loci, some of the genetic variants that were originally detected to affect a risk of coronary artery disease were also associated 
with ischemic stroke (16-18), suggesting a shared genetic architecture. Although ischemic stroke and coronary artery disease have been suggested to have a shared genetic architecture in Caucasian populations, the genes that confer susceptibility to the two conditions in Japanese individuals have not been identified definitively.

The aim of the present study was to examine the possible association of ischemic stroke in Japanese individuals with the 29 single-nucleotide polymorphisms (SNPs) previously identified as susceptibility loci for coronary artery disease by the meta-analyses of GWASs in Caucasian populations $(14,15)$.

\section{Materials and methods}

Study population. The study subjects comprised 3,187 Japanese individuals (894 subjects with ischemic stroke and 2,293 controls) who either visited the outpatient clinics or were admitted to the participating hospitals (Gifu Prefectural Tajimi Hospital, Tajimi; Gifu Prefectural General Medical Center, Gifu; Inabe General Hospital, Inabe; Japanese Red Cross Nagoya First Hospital, Nagoya; Hirosaki University Hospital and Hirosaki Stroke Center, Hirosaki, Japan) between 2002 and 2012. The diagnosis of ischemic stroke was based on the occurrence of a new and abrupt focal neurological deficit, with neurological symptoms and signs persisting for $>24 \mathrm{~h}$; it was confirmed by positive findings in computed tomography or magnetic resonance imaging (or both) of the head. The type of stroke was determined according to the Classification of Cerebrovascular Diseases III (19). Individuals with cardiogenic embolic infarction, lacunar infarction alone, transient ischemic attack, moyamoya disease or cerebral venous sinus thrombosis were excluded from the study. Control individuals had no history of ischemic or hemorrhagic stroke, or other cerebral diseases; of coronary artery disease, aortic aneurysm, or peripheral arterial occlusive disease; or of other thrombotic, embolic or hemorrhagic disorders.

Hypertension was defined as individuals who either had systolic blood pressure $\geq 140 \mathrm{mmHg}$ or diastolic blood pressure $\geq 90 \mathrm{mmHg}$, or had been administered antihypertensive medication. Dyslipidemia was defined as individuals who had either a serum concentration of triglycerides of $\geq 1.65 \mathrm{mmol} / 1$, a serum high-density lipoprotein (HDL)-cholesterol of $<1.04 \mathrm{mmol} / 1$, a serum low-density lipoprotein (LDL)-cholesterol of $\geq 3.64 \mathrm{mmol} / \mathrm{l}$, or had been administered antidyslipidemic medication. Diabetes mellitus was defined as individuals who either had a fasting plasma glucose level of $\geq 6.93 \mathrm{mmol} / 1$ or blood glycosylated hemoglobin (hemoglobin A1c) content of $\geq 6.5 \%$, or had been administered antidiabetes medication. Chronic kidney disease (CKD) was defined as individuals who had an estimated glomerular filtration rate (eGFR) of $<60 \mathrm{ml} \mathrm{min}^{-1} 1.73 \mathrm{~m}^{-2}$. The eGFR was calculated with the use of the simplified prediction equation derived from the modified version of that described in the Modification of Diet in Renal Disease study, as proposed by the Japanese Society of Nephrology: eGFR $\left(\mathrm{ml} / \mathrm{min} / 1.73 \mathrm{~m}^{2}\right)=194 \mathrm{x}$ age $(\text { years })^{-0.287} \mathrm{x}$ serum creatinine $(\mathrm{mg} / \mathrm{dl})^{-1.094}$ (x 0.739 if female) (20).

The study protocol complied with the Declaration of Helsinki and was approved by the Committees on the Ethics of Human Research of Mie University Graduate School of Medicine, Hirosaki University Graduate School of Medicine
(Hirosaki, Japan) and the participating hospitals. Written informed consent was obtained from each participant.

Selection and genotyping of polymorphisms. The SNPs that were shown to be significantly associated with coronary artery disease or myocardial infarction were searched in Caucasian populations by the meta-analyses of GWASs $(14,15)$. These SNPs were examined with the SNP database (dbSNP; National Center for Biotechnology Information, Bethesda, MD, USA; http://www.ncbi.nlm.nih.gov/SNP/) to find SNPs with a minor allele frequency of $\geq 0.015$ in a Japanese population. A total of 29 SNPs (21) were selected and the possible association with ischemic stroke was examined.

Venous blood $(7 \mathrm{ml})$ was collected into tubes containing $50 \mathrm{mmol} / 1$ ethylenediaminetetraacetic acid (disodium salt), the peripheral blood leukocytes were isolated and genomic DNA was extracted from these cells with a DNA extraction kit (Genomix; Talent, Trieste, Italy). Genotypes of SNPs were determined at G\&G Science Co., Ltd. (Fukushima, Japan) by a method that combines the polymerase chain reaction and sequence-specific oligonucleotide probes with suspension array technology (Luminex, Austin, TX, USA). Primers, probes and other conditions for genotyping of SNPs examined in the study are as described previously (21). The overall call rate of 29 SNP genotyping was 99\%. Detailed genotyping methodology was also as described previously (22-24).

Statistical analysis. Quantitative data were compared between two groups by the Mann-Whitney U test, given that the data were not normally distributed $(\mathrm{P}<0.01$ by the Kolmogorov-Smirnov and Lilliefors test). Categorical data were compared by the $\chi^{2}$ test. Allele frequencies were estimated by the gene counting method. Multivariable logistic regression analysis was performed with ischemic stroke as a dependent variable and independent variables including age, gender ( 0 , female; 1 , male), body mass index (BMI), smoking status (0 non-smoker; 1 current or former smoker), history of hypertension, diabetes mellitus and dyslipidemia (0 no history; 1 positive history), and each genotype; and the P-value, odds ratio and $95 \%$ confidence interval were calculated. Genotypes of each polymorphism were assessed according to dominant $[0 \mathrm{AA} ; 1 \mathrm{AB}+\mathrm{BB}$ (A, major allele; $\mathrm{B}$, minor allele $)]$, recessive $(0 \mathrm{AA}+\mathrm{AB} ; 1 \mathrm{BB})$ and additive genetic models. Additive models comprised additive 1 (AB vs. AA) and 2 (BB vs. AA) models, which were analyzed simultaneously with a single statistical model. $\mathrm{P}<0.05$ was considered to indicate a statistically significant difference. The statistical tests were performed with JMP version 5.1 and JMP Genomics version 6.0 software (SAS Institute Inc., Cary, NC, USA).

\section{Results}

Subject characteristics. The characteristics of the 3,187 study subjects are shown in Table I. Age, the frequency of men, the prevalence of smoking, hypertension, dyslipidemia, diabetes mellitus and CKD, as well as systolic and diastolic blood pressure, serum concentrations of triglycerides, LDL-cholesterol and creatinine, and fasting plasma glucose level were greater, whereas serum concentrations of HDL-cholesterol and eGFR 
Table I. Characteristics of subjects with ischemic stroke and the controls.

\begin{tabular}{|c|c|c|c|}
\hline Characteristics & Ischemic stroke & Controls & P-value \\
\hline No. of subjects & 894 & 2,293 & \\
\hline Age, years & $68.8 \pm 10.3$ & $62.3 \pm 11.8$ & $<0.0001$ \\
\hline Gender, \% (male/female) & $61.6 / 38.4$ & $44.7 / 55.3$ & $<0.0001$ \\
\hline Body mass index, $\mathrm{kg} / \mathrm{m}^{2}$ & $23.6 \pm 3.6$ & $23.7 \pm 3.6$ & 0.5420 \\
\hline Current or former smoker, $\%$ & 27.5 & 22.7 & 0.0148 \\
\hline Hypertension, \% & 75.3 & 44.3 & $<0.0001$ \\
\hline Systolic blood pressure, $\mathrm{mmHg}$ & $152 \pm 28$ & $141 \pm 24$ & $<0.0001$ \\
\hline Diastolic blood pressure, $\mathrm{mmHg}$ & $84 \pm 17$ & $79 \pm 14$ & $<0.0001$ \\
\hline Dyslipidemia, \% & 39.2 & 29.6 & $<0.0001$ \\
\hline Serum triglyceride, $\mathrm{mmol} / \mathrm{l}$ & $1.60 \pm 1.01$ & $1.50 \pm 1.10$ & 0.0002 \\
\hline Serum HDL-cholesterol, mmol/1 & $1.24 \pm 0.37$ & $1.47 \pm 0.40$ & $<0.0001$ \\
\hline Serum LDL-cholesterol, mmol/1 & $3.13 \pm 0.92$ & $3.02 \pm 0.85$ & 0.0472 \\
\hline Diabetes mellitus, $\%$ & 42.7 & 20.0 & $<0.0001$ \\
\hline Fasting plasma glucose, $\mathrm{mmol} / \mathrm{l}$ & $7.46 \pm 3.12$ & $6.36 \pm 3.40$ & $<0.0001$ \\
\hline Chronic kidney disease, $\%$ & 39.4 & 28.6 & $<0.0001$ \\
\hline Serum creatinine, $\mu \mathrm{mol} / 1$ & $90.4 \pm 94.6$ & $83.2 \pm 98.5$ & $<0.0001$ \\
\hline $\mathrm{eGFR}, \mathrm{m} / \mathrm{min} / 1.73 \mathrm{~m}^{2}$ & $66.6 \pm 23.2$ & $70.4 \pm 23.2$ & $<0.0001$ \\
\hline
\end{tabular}

Quantitative data are mean \pm standard deviation. Hypertension: Systolic blood pressure of $\geq 140 \mathrm{mmHg}$ or diastolic blood pressure of $\geq 90 \mathrm{mmHg}$ (or both), or taking of antihypertensive medication. Dyslipidemia: A serum concentration of triglycerides of $\geq 1.65 \mathrm{mmol} / \mathrm{l}$, a serum high-density lipoprotein (HDL)-cholesterol of $<1.04 \mathrm{mmol} / 1$, a serum low-density lipoproitein (LDL)-cholesterol of $\geq 3.64 \mathrm{mmol} / \mathrm{l}$, or taking of antidyslipidemic medication. Diabetes mellitus: A fasting blood glucose level of $\geq 6.93 \mathrm{mmol} / \mathrm{l}$ or a blood glycosylated hemoglobin content of $\geq 6.5 \%$ (or both), or taking of antidiabetes medication. Chronic kidney disease: Estimated glomerular filtration rate $(\mathrm{eGFR})<60 \mathrm{ml} / \mathrm{min} / 1.73 \mathrm{~m}{ }^{2}$. Quantitative data are compared between the two groups by the Mann-Whitney U test.

Table II. Comparisons of genotype distributions and allele frequencies of rs9319428 of FLT1, rs2075650 of TOMM40 or rs273909 of SLC22A4 by the $\chi^{2}$ test between subjects with ischemic stroke and controls.

\begin{tabular}{|c|c|c|c|c|c|c|c|}
\hline Gene & dbSNP & Polymorphism & Ischemic stroke, n (\%) & Control, n (\%) & Call rate $(\%)$ & $\begin{array}{c}\text { P-value } \\
\text { (genotype) }\end{array}$ & $\begin{array}{l}\text { P-value } \\
\text { (allele) }\end{array}$ \\
\hline \multirow[t]{4}{*}{ FLT1 } & \multirow[t]{4}{*}{ rs9319428 } & $\mathrm{G} \rightarrow \mathrm{A}$ & & & \multirow[t]{4}{*}{99.3} & \multirow[t]{4}{*}{0.1319} & \multirow[t]{4}{*}{$0.0471^{\mathrm{a}}$} \\
\hline & & GG & $331(37.0)$ & $926(40.8)$ & & & \\
\hline & & GA & $421(47.1)$ & $1,021(45.0)$ & & & \\
\hline & & AA & $142(15.9)$ & $324(14.3)$ & & & \\
\hline \multirow[t]{4}{*}{ TOMM40 } & \multirow[t]{4}{*}{ rs2075650 } & $\mathrm{G} \rightarrow \mathrm{A}$ & & & \multirow[t]{4}{*}{99.4} & \multirow[t]{4}{*}{$0.0043^{\mathrm{a}}$} & \multirow[t]{4}{*}{$0.0102^{\mathrm{a}}$} \\
\hline & & AA & $640(71.6)$ & $1,557(68.4)$ & & & \\
\hline & & $\mathrm{AG}$ & $239(26.7)$ & $629(27.7)$ & & & \\
\hline & & GG & $15(1.7)$ & $89(3.9)$ & & & \\
\hline \multirow[t]{4}{*}{ SLC22A4 } & \multirow[t]{4}{*}{ rs273909 } & $\mathrm{T} \rightarrow \mathrm{C}$ & & & \multirow[t]{4}{*}{99.7} & \multirow[t]{4}{*}{$0.0232^{\mathrm{a}}$} & \multirow[t]{4}{*}{$0.0097^{\mathrm{a}}$} \\
\hline & & $\mathrm{TT}$ & $872(97.5)$ & $2,180(95.5)$ & & & \\
\hline & & $\mathrm{TC}$ & $21(2.4)$ & $101(4.4)$ & & & \\
\hline & & $\mathrm{CC}$ & $1(0.1)$ & $2(0.1)$ & & & \\
\hline
\end{tabular}

${ }^{\mathrm{a}} \mathrm{P}<0.05$. FLT1, fms-related tyrosine kinase 1 gene; TOMM40, translocase of outer mitochondrial membrane 40 homolog gene; SLC22A4, solute carrier family 22 , member 4 gene; dbSNP, single nucleotide polymorphism database.

were lower in subjects with ischemic stroke compared to the controls.

Comparisons of genotype distributions or allele frequencies. The genotype distributions and allele frequencies were compared by the $\chi^{2}$ test and revealed that 3 SNPs were significantly $(\mathrm{P}<0.05)$ associated with the prevalence of ischemic stroke (Table II). The genotype distributions and allele frequencies of rs2075650 of the translocase of outer mitochondrial membrane 40 homolog (TOMM40) gene and of rs273909 
of the solute carrier family 22 , member 4 (SLC22A4) gene were significantly associated with the prevalence of ischemic stroke. Allele frequencies of rs9319428 of the fms-related tyrosine kinase 1 gene ( $F L T 1)$ were also significantly associated with ischemic stroke. These SNPs were further examined by multivariable logistic regression analysis with adjustment for covariates.

Multivariable logistic regression analysis. The multivariable logistic regression analysis was performed with adjustment for age, gender, BMI, smoking status and the prevalence of hypertension, diabetes mellitus and dyslipidemia and revealed that rs2075650 of TOMM40 (recessive and additive 2 models) and rs273909 of SLC22A4 (dominant and additive 1 models), but not rs9319428 of $F L T 1$, were significantly $(\mathrm{P}<0.05)$ associated with ischemic stroke, with the minor $\mathrm{G}$ and $\mathrm{C}$ alleles, respectively, being protective against this condition (Table III).

Association of TOMM4O and SLC22A4 polymorphisms with the prevalence of the clinical phenotypes. Subsequently, the association of rs 2075650 of TOMM40 or rs 273909 of SLC22A4 to the prevalence of hypertension, dyslipidemia, diabetes mellitus or CKD was examined in all the subjects (Table IV). The rs2075650 of TOMM4O or rs273909 of SLC22A4 was significantly $(\mathrm{P}<0.05)$ associated with the prevalence of dyslipidemia (dominant model) or CKD (recessive model), respectively.

Association of TOMM4O and SLC22A4 polymorphisms with the prevalence with the clinical parameters. The associations of rs2075650 of TOMM40 or rs273909 of SLC22A4 were examined with the clinical parameters including systolic, diastolic and mean blood pressure, pulse pressure, serum concentrations of triglycerides, LDL-cholesterol, HDL-cholesterol, creatinine, fasting plasma glucose level and eGFR (Table V). To avoid the effects of medical treatment on clinical parameters, the corresponding controls were examined for hypertension, dyslipidemia, diabetes mellitus or CKD. The rs2075650 of TOMM40 was not associated with any clinical parameter, whereas rs273909 of SLC22A4 was associated with fasting plasma glucose level (recessive model).

\section{Discussion}

The association of 29 SNPs identified by the meta-analyses of GWASs for coronary artery disease in Caucasian populations $(14,15)$ to the prevalence of ischemic stroke in Japanese individuals was examined. The present study showed that rs2075650 of TOMM40 and rs273909 of SLC22A4 were significantly associated with ischemic stroke with the minor $\mathrm{G}$ and $\mathrm{C}$ allele, respectively, being protective against this condition.

TOMM40 is located at chromosome $19 \mathrm{q} 13$ (NCBI Gene) and encodes a channel-forming subunit of multisubunit translocase of the outer mitochondrial membrane (TOM complex), which plays a role in cytoplasmic protein transport into the mitochondria $(25,26)$. The rs 2075650 of TOMM40 was shown to be associated with longevity, Alzheimer's disease and plasma concentrations of total cholesterol and C-reactive protein (27-30). The previous study suggested that rs 2075650 
Table IV. Associations of rs2075650 of TOMM40 or rs273909 of SLC22A4 with the prevalence of hypertension, dyslipidemia, diabetes mellitus or CKD as determined by the $\chi^{2}$ test.

\begin{tabular}{|c|c|c|c|c|c|}
\hline \multirow{2}{*}{$\begin{array}{l}\text { Clinical phenotype } \\
\text { TOMM4O (rs2075650) }\end{array}$} & \multicolumn{3}{|c|}{ Genotype, n (\%) } & \multirow[t]{2}{*}{ P-value (dominant) } & \multirow[t]{2}{*}{ P-value (recessive } \\
\hline & $A A$ & $A G$ & $G G$ & & \\
\hline \multicolumn{6}{|l|}{ Hypertension } \\
\hline Case & $1,169(69.4)$ & 467 (27.7) & $48(2.9)$ & 0.9067 & 0.1466 \\
\hline Control & $1,028(69.2)$ & $401(27.0)$ & $56(3.8)$ & & \\
\hline \multicolumn{6}{|l|}{ Dyslipidemia } \\
\hline Case & $685(66.8)$ & $301(29.4)$ & $39(3.8)$ & $0.0349^{\mathrm{a}}$ & 0.2531 \\
\hline Control & $1,512(70.5)$ & $567(26.5)$ & $65(3.0)$ & & \\
\hline \multicolumn{6}{|l|}{ Diabetes mellitus } \\
\hline Case & 601 (71.6) & $212(25.3)$ & $26(3.1)$ & 0.0913 & 0.7288 \\
\hline Control & $1,596(68.5)$ & $656(28.2)$ & $78(3.3)$ & & \\
\hline \multicolumn{6}{|l|}{ CKD } \\
\hline Case & $531(69.2)$ & 206 (26.9) & $30(3.9)$ & 0.7238 & 0.3235 \\
\hline Control & $1,161(70.0)$ & 447 (26.9) & $52(3.1)$ & & \\
\hline SLC22A4 (rs273909) & $T T$ & $T C$ & $C C$ & & \\
\hline \multicolumn{6}{|l|}{ Hypertension } \\
\hline Case & $1,622(96.0)$ & $66(3.9)$ & $1(0.1)$ & 0.9205 & 0.4911 \\
\hline Control & $1,430(96.1)$ & $56(3.8)$ & $2(0.1)$ & & \\
\hline \multicolumn{6}{|l|}{ Dyslipidemia } \\
\hline Case & $982(95.5)$ & $44(4.3)$ & $2(0.2)$ & 0.2787 & 0.2038 \\
\hline Control & $2,070(96.3)$ & $78(3.6)$ & $1(0.1)$ & & \\
\hline \multicolumn{6}{|l|}{ Diabetes mellitus } \\
\hline Case & $811(96.6)$ & $29(3.4)$ & $0(0.0)$ & 0.4020 & 0.2988 \\
\hline Control & $2,241(95.9)$ & $93(4.0)$ & $3(0.1)$ & & \\
\hline \multicolumn{6}{|l|}{ CKD } \\
\hline Case & $738(96.1)$ & $28(3.6)$ & $2(0.3)$ & 0.5881 & $0.0372^{\mathrm{a}}$ \\
\hline Control & $1,593(95.6)$ & $73(4.4)$ & $0(0.0)$ & & \\
\hline
\end{tabular}

${ }^{\mathrm{a}} \mathrm{P}<0.05$. Hypertension: Systolic blood pressure of $\geq 140 \mathrm{mmHg}$ or diastolic blood pressure of $\geq 90 \mathrm{mmHg}$ (or both), or taking of antihypertensive medication. Dyslipidemia: A serum concentration of triglycerides of $\geq 1.65 \mathrm{mmol} / \mathrm{l}$, a serum high density lipoprotein-cholesterol of $<1.04 \mathrm{mmol} / \mathrm{l}$, a serum low density lipoproitein-cholesterol of $\geq 3.64 \mathrm{mmol} / \mathrm{l}$, or taking of antidyslipidemic medication. Diabetes mellitus: A fasting blood glucose level of $\geq 6.93 \mathrm{mmol} / \mathrm{l}$ or a blood glycosylated hemoglobin content of $\geq 6.5 \%$ (or both), or taking of antidiabetes medication. CKD: Estimated glomerular filtration rate $<60 \mathrm{ml} / \mathrm{min} / 1.73 \mathrm{~m}^{2}$. TOMM40, translocase of outer mitochondrial membrane 40 homolog gene; SLC22A4, solute carrier family 22, member 4 gene; CKD, chronic kidney disease.

may increase a risk of carotid artery disease by promoting the formation of smaller, denser LDL particles (31). The present results showed that rs2075650 was associated with the prevalence of dyslipidemia but not to the serum lipid profiles, suggesting that the effect of this SNP on the development of dyslipidemia may not be significant.

The rs2075650 located in the intron 2 of TOMM40 (NCBI Gene) is a proxy of the SNPs that define alleles of the apolipoprotein E gene (APOE) (32). Given that the rs2075650 of TOMM40 is in strong linkage disequilibrium with rs429358 (C $\rightarrow \mathrm{T}$, Arg130Cys) of APOE, certain clinical implications may originate from $A P O E(27,32)$. Although the minor C allele of rs429358 of APOE was shown to be associated with the increased serum LDL-cholesterol level, as well as the increased risk of coronary artery disease and Alzheimer's disease $(27,33,34)$, the association of this SNP with ischemic stroke has not been determined (35). The present study shows that rs2075650 of TOMM40 was associated with ischemic stroke with the minor $\mathrm{G}$ allele being protective against this condition, although the underlying molecular mechanism remains unclear.

SLC22A4, located at chromosome 5q31, is abundantly expressed in the kidney, skeletal muscle, bone marrow and trachea, and weakly expressed in numerous other organs (36). SLC22A4 encodes carnitine/organic cation transporter (OCTN1), which transports ergothioneine. Ergothioneine was shown to have antioxidative and cytoprotective functions $(37,38)$ and to protect cardiovascular tissue against oxidative injury during ischemia and reperfusion (39). Ergothioneine decreased the expression of the adhesion molecules, including vascular cell adhesion molecule 1, intercellular adhesion molecule 1 and selectin E, and inhibited binding of monocytes to the endothelium (40). These observations suggest that the immunomodulatory effects 
Table V. Associations of rs2075650 of TOMM40 or rs273909 of SLC22A4 with the clinical parameters among corresponding controls for hypertension, dyslipidemia, diabetes mellitus or chronic kidney disease.

\begin{tabular}{|c|c|c|c|c|c|}
\hline Clinical parameter & & Genotype & & P-value (dominant) & P-value (recessive) \\
\hline \multicolumn{6}{|l|}{ Controls for hypertension } \\
\hline TOMM40 (rs2075650) & $A A$ & $A G$ & $G G$ & & \\
\hline Systolic blood pressure, $\mathrm{mmHg}$ & $121 \pm 11$ & $122 \pm 11$ & $116 \pm 10$ & 0.9519 & 0.0782 \\
\hline Diastolic blood pressure, $\mathrm{mmHg}$ & $71 \pm 9$ & $71 \pm 9$ & $69 \pm 12$ & 0.5835 & 0.6733 \\
\hline Mean blood pressure, $\mathrm{mmHg}$ & $88 \pm 9$ & $88 \pm 9$ & $85 \pm 10$ & 0.7415 & 0.2788 \\
\hline Pulse pressure, $\mathrm{mmHg}$ & $50 \pm 11$ & $51 \pm 10$ & $47 \pm 12$ & 0.3384 & 0.2738 \\
\hline SLC22A4 (rs273909) & $T T$ & $T C$ & $C C$ & & \\
\hline Systolic blood pressure, $\mathrm{mmHg}$ & $121 \pm 11$ & $126 \pm 10$ & 128 & 0.0659 & 0.6491 \\
\hline Diastolic blood pressure, $\mathrm{mmHg}$ & $71 \pm 9$ & $72 \pm 10$ & 78 & 0.8114 & 0.4374 \\
\hline Mean blood pressure, $\mathrm{mmHg}$ & $88 \pm 9$ & $90 \pm 9$ & 95 & 0.3947 & 0.3570 \\
\hline Pulse pressure, $\mathrm{mmHg}$ & $50 \pm 11$ & $54 \pm 19$ & 50 & 0.0805 & 0.9611 \\
\hline \multicolumn{6}{|l|}{ Controls for dyslipidemia } \\
\hline TOMM40 (rs2075650) & $A A$ & $A G$ & $G G$ & & \\
\hline Serum triglycerides, $\mathrm{mmol} / \mathrm{l}$ & $1.27 \pm 0.74$ & $1.31 \pm 0.72$ & $1.33 \pm 0.66$ & 0.1505 & 0.1883 \\
\hline Serum LDL-cholesterol, mmol/l & $2.68 \pm 0.62$ & $2.74 \pm 0.62$ & $2.76 \pm 0.66$ & 0.0811 & 0.4884 \\
\hline Serum HDL-cholesterol, mmol/l & $1.39 \pm 0.39$ & $1.37 \pm 0.37$ & $1.30 \pm 0.38$ & 0.3865 & 0.2344 \\
\hline SLC22A4 (rs273909) & $T T$ & $T C$ & $C C$ & & \\
\hline Serum triglycerides, $\mathrm{mmol} / \mathrm{l}$ & $1.29 \pm 0.74$ & $1.18 \pm 0.57$ & ND & 0.1587 & ND \\
\hline Serum LDL-cholesterol, mmol/l & $2.70 \pm 0.63$ & $2.83 \pm 0.56$ & ND & 0.1461 & ND \\
\hline Serum HDL-cholesterol, mmol/l & $1.38 \pm 0.39$ & $1.40 \pm 0.36$ & ND & 0.3983 & ND \\
\hline \multicolumn{6}{|l|}{ Controls for diabetes mellitus } \\
\hline TOMM40 (rs2075650) & $A A$ & $A G$ & $G G$ & & \\
\hline Fasting plasma glucose, mmol/1 & $5.17 \pm 0.87$ & $5.17 \pm 0.85$ & $5.24 \pm 0.83$ & 0.9055 & 0.5534 \\
\hline SLC22A4 (rs273909) & $T T$ & $T C$ & $C C$ & & \\
\hline Fasting plasma glucose, mmol/1 & $5.18 \pm 0.87$ & $5.06 \pm 0.72$ & $6.69 \pm 0.20$ & 0.4405 & $0.0228^{\mathrm{a}}$ \\
\hline \multicolumn{6}{|l|}{ Controls for chronic kidney disease } \\
\hline TOMM40 (rs2075650) & $A A$ & $A G$ & $G G$ & & \\
\hline Serum creatinine, $\mu \mathrm{mol} / 1$ & $61.1 \pm 12.9$ & $60.8 \pm 12.3$ & $64.0 \pm 12.3$ & 0.9623 & 0.0783 \\
\hline eGFR (ml/min/1.73 m²) & $80.6 \pm 16.6$ & $80.0 \pm 20.7$ & $79.6 \pm 17.5$ & 0.2028 & 0.6268 \\
\hline SLC22A4 (rs273909) & $T T$ & $T C$ & $C C$ & & \\
\hline Serum creatinine, $\mu \mathrm{mol} / 1$ & $61.2 \pm 12.8$ & $60.4 \pm 11.4$ & ND & 0.6562 & ND \\
\hline eGFR (ml/min/1.73 m²) & $80.4 \pm 17.9$ & $77.6 \pm 15.6$ & ND & 0.7419 & ND \\
\hline
\end{tabular}

${ }^{\mathrm{a}} \mathrm{P}<0.05$. LDL, low-density lipoprotein; HDL, high-density lipoprotein; eGFR, estimated glomerular filtration rate; ND, not determined; TOMM40, translocase of outer mitochondrial membrane 40 homolog gene; SLC22A4, solute carrier family 22, member 4 gene. Data are compared between the two groups (dominant or recessive model) by the Mann-Whitney U test.

of ergothioneine may be beneficial, owing to inhibition of the atherogenic action of pro-inflammatory cytokines and adhesion molecules $(41,42)$. Several SNPs of SLC22A4 were shown to be associated with chronic inflammatory disease, such as Crohn's disease, ulcerative colitis, rheumatoid arthritis and type 1 diabetes mellitus (43-46). In the present study, rs273909 was associated with the prevalence of CKD but not to the serum concentration of creatinine or eGFR. This SNP was also associated with fasting plasma glucose level but not to the prevalence of diabetes mellitus. These observations suggest that the effect of rs273909 on the development of CKD or diabetes mellitus may not be significant. The present study has now shown that rs273909 of SLC22A4 was significantly associated with ischemic stroke with the minor $\mathrm{C}$ allele being protective against this condition, although the underlying mechanism remains to be elucidated. The effect of rs273909 on the expression or molecular structure of OCTN1 also remains unknown.

The meta-analysis of GWASs has identified several loci that confer shared susceptibility to ischemic stroke and coronary artery disease in Caucasians (18). Among these loci, we have examined rs1122608 of the SWI/SNF-related, matrix-associated, actin-dependent regulator of chromatin, subfamily a, member 4 gene and rs12413409 of the cyclin and 
CBS domain divalent metal cation transport mediator 2 gene. However, neither rs1122608 nor rs12413409 was associated with ischemic stroke in Japanese individuals. We previously showed that 6 genetic variants among the same 29 SNPs were associated with myocardial infarction in Japanese individuals (21), but no SNP was associated with ischemic stroke and myocardial infarction.

There were several limitations in the present study; i) given that the results were not replicated, validation of these findings is required in other independent subject panels or in other ethnic groups; ii) it is possible that rs2075650 of TOMM4O or rs 273909 of SLC22A4 is in linkage disequilibrium with other polymorphisms in the same gene or in other nearby genes that are actually responsible for the development of ischemic stroke; and iii) the functional relevance of rs2075650 or rs273909 to pathogenesis of ischemic stroke remains to be elucidated.

In conclusion, TOMM4O and SLC22A4 may be susceptibility loci for ischemic stroke in Japanese individuals. Determination of the genotypes of these SNPs may prove informative for assessment of the genetic risk for ischemic stroke in such individuals.

\section{Acknowledgements}

The present study was supported by a Collaborative Research grant from the Gifu Prefectural General Medical Center (no. H24-26 to Y.Y.) and a Grant-in-Aid for Scientific Research from the Ministry of Education, Culture, Sports, Science and Technology of Japan (no. 24590746 to Y.Y.).

\section{References}

1. Tournier-Lasserve E: New players in the genetics of stroke. N Engl J Med 347: 1711-1712, 2002.

2. Bak S, Gaist D, Sindrup SH, Skytthe A and Christensen K: Genetic liability in stroke: A long-term follow-up study of Danish twins. Stroke 33: 769-774, 2002.

3. Go AS, Mozaffarian D, Roger VL, Benjamin EJ, Berry JD, Blaha MJ, Dai S, Ford ES, Fox CS, Franco S, et al; American Heart Association Statistics Committee and Stroke Statistics Subcommittee: Heart disease and stroke statistics - 2014 update: A report from the American Heart Association. Circulation 129: e28-e292, 2014.

4. Bonita R: Epidemiology of stroke. Lancet 339: 342-344, 1992.

5. Warlow C, Sudlow C, Dennis M, Wardlaw J and Sandercock P: Stroke. Lancet 362: 1211-1224, 2003.

6. Dichgans M: Genetics of ischaemic stroke. Lancet Neurol 6: 149-161, 2007.

7. Roberts R and Stewart AF: The genetics of coronary artery disease. Curr Opin Cardiol 27: 221-227, 2012.

8. Banerjee A, Lim CC, Silver LE, Welch SJ, Banning AP and Rothwell PM: Familial history of stroke is associated with acute coronary syndromes in women. Circ Cardiovasc Genet 4: 9-15, 2011.

9. Ikram MA, Seshadri S, Bis JC, Fornage M, DeStefano AL, Aulchenko YS, Debette S, Lumley T, Folsom AR, van den Herik EG, et al: Genomewide association studies of stroke. N Engl J Med 360: 1718-1728, 2009.

10. Matarín M, Brown WM, Scholz S, Simón-Sánchez J, Fung HC, Hernandez D, Gibbs JR, De Vrieze FW, Crews C, Britton A, et al: A genome-wide genotyping study in patients with ischaemic stroke: Initial analysis and data release. Lancet Neurol 6: 414-420, 2007.

11. Yamada Y, Fuku N, Tanaka M, Aoyagi Y, Sawabe M, Metoki N, Yoshida H, Satoh K, Kato K, Watanabe S, et al: Identification of CELSR1 as a susceptibility gene for ischemic stroke in Japanese individuals by a genome-wide association study. Atherosclerosis 207: 144-149, 2009.
12. Traylor M, Farrall M, Holliday EG, Sudlow C, Hopewell JC, Cheng YC, Fornage M, Ikram MA, Malik R, Bevan S, et al; Australian Stroke Genetics Collaborative, Wellcome Trust Case Control Consortium 2 (WTCCC2); International Stroke Genetics Consortium: Genetic risk factors for ischaemic stroke and its subtypes (the METASTROKE collaboration): A meta-analysis of genome-wide association studies. Lancet Neurol 11: 951-962, 2012.

13. Holliday EG, Maguire JM, Evans TJ, Koblar SA, Jannes J, Sturm JW, Hankey GJ, Baker R, Golledge J, Parsons MW, et al; Australian Stroke Genetics Collaborative; International Stroke Genetics Consortium; Wellcome Trust Case Control Consortium 2: Common variants at $6 \mathrm{p} 21.1$ are associated with large artery atherosclerotic stroke. Nat Genet 44: 1147-1151, 2012.

14. Schunkert H, König IR, Kathiresan S, Reilly MP, Assimes TL, Holm H, Preuss M, Stewart AF, Barbalic M, Gieger C, et al; Cardiogenics; CARDIoGRAM Consortium: Large-scale association analysis identifies 13 new susceptibility loci for coronary artery disease. Nat Genet 43: 333-338, 2011.

15. Deloukas P, Kanoni S, Willenborg C, Farrall M, Assimes TL, Thompson JR, Ingelsson E, Saleheen D, Erdmann J, Goldstein BA, et al; CARDIoGRAMplusC4D Consortium; DIAGRAM Consortium; CARDIOGENICS Consortium; MuTHER Consortium; Wellcome Trust Case Control Consortium: Large-scale association analysis identifies new risk loci for coronary artery disease. Nat Genet 45: 25-33, 2013.

16. Gschwendtner A, Bevan S, Cole JW, Plourde A, Matarin M, Ross-Adams H, Meitinger T, Wichmann E, Mitchell BD, Furie $\mathrm{K}$, et al; International Stroke Genetics Consortium: Sequence variants on chromosome 9p21.3 confer risk for atherosclerotic stroke. Ann Neurol 65: 531-539, 2009.

17. Williams FM, Carter AM, Hysi PG, Surdulescu G, Hodgkiss D, Soranzo N, Traylor M, Bevan S, Dichgans M, Rothwell PM, et al; EuroCLOT Investigators; Wellcome Trust Case Control Consortium 2; MOnica Risk, Genetics, Archiving and Monograph; MetaStroke; International Stroke Genetics Consortium: Ischemic stroke is associated with the ABO locus: The EuroCLOT study. Ann Neurol 73: 16-31, 2013.

18. Dichgans M, Malik R, König IR, Rosand J, Clarke R, Gretarsdottir S, Thorleifsson G, Mitchell BD, Assimes TL, Levi C, et al; METASTROKE Consortium; CARDIoGRAM Consortium; C4D Consortium; International Stroke Genetics Consortium: Shared genetic susceptibility to ischemic stroke and coronary artery disease: A genome-wide analysis of common variants. Stroke 45: 24-36, 2014.

19. Special report from the National Institute of Neurological Disorders and Stroke. Classification of cerebrovascular diseases III. Stroke 21: 637-676, 1990.

20. Matsuo S, Imai E, Horio M, Yasuda Y, Tomita K, Nitta K, Yamagata K, Tomino Y, Yokoyama $\mathrm{H}$ and Hishida A; Collaborators developing the Japanese equation for estimated GFR: Revised equations for estimated GFR from serum creatinine in Japan. Am J Kidney Dis 53: 982-992, 2009.

21. Matsuoka R, Abe S, Tokoro F, et al: Association of six genetic variants with myocardial infarction. Int J Mol Med 35: 1451-1459, 2015.

22. Yamada Y, Nishida T, Ichihara S, Sawabe M,Fuku N, Nishigaki Y, Aoyagi Y, Tanaka M, Fujiwara Y, Yoshida H, et al: Association of a polymorphism of BTN2A1 with myocardial infarction in East Asian populations. Atherosclerosis 215: 145-152, 2011

23. Yamada Y, Nishida T, Ichihara S, et al: Identification of chromosome 3q28 and ALPK1 as susceptibility loci for chronic kidney disease in Japanese individuals by a genome-wide association study. J Med Genet 50: 410-418, 2013.

24. Itoh Y, Mizuki N, Shimada T, Azuma F, Itakura M, Kashiwase K, Kikkawa E, Kulski JK, Satake M and Inoko H: High-throughput DNA typing of HLA-A, -B, -C and -DRB1 loci by a PCR-SSOP-Luminex method in the Japanese population. Immunogenetics 57: 717-729, 2005.

25. Koehler CM, Merchant S and Schatz G: How membrane proteins travel across the mitochondrial intermembrane space. Trends Biochem Sci 24: 428-432, 1999.

26. Humphries AD, Streimann IC, Stojanovski D, Johnston AJ, Yano M, Hoogenraad NJ and Ryan MT: Dissection of the mitochondrial import and assembly pathway for human Tom40. J Biol Chem 280: 11535-11543, 2005.

27. Deelen J, Beekman M, Uh HW, et al: Genome-wide association study identifies a single major locus contributing to survival into old age; the APOE locus revisited. Aging Cell 10: 686-698, 2011. 
28. Feulner TM, Laws SM, Friedrich P, Wagenpfeil S, Wurst SH Riehle C, Kuhn KA, Krawczak M, Schreiber S, Nikolaus S, et al: Examination of the current top candidate genes for AD in a genome-wide association study. Mol Psychiatry 15: 756-766, 2010

29. Aulchenko YS, Ripatti S, Lindqvist I, et al; ENGAGE Consortium: Loci influencing lipid levels and coronary heart disease risk in 16 European population cohorts. Nat Genet 41: 47-55, 2009.

30. Reiner AP, Barber MJ, Guan Y, Ridker PM, Lange LA, Chasman DI, Walston JD, Cooper GM, Jenny NS, Rieder MJ, et al: Polymorphisms of the HNF1A gene encoding hepatocyte nuclear factor-1 alpha are associated with C-reactive protein. Am J Hum Genet 82: 1193-1201, 2008.

31. Ronald J, Rajagopalan R, Ranchalis JE, Marshall JK, Hatsukami TS, Heagerty PJ and Jarvik GP: Analysis of recently identified dyslipidemia alleles reveals two loci that contribute to risk for carotid artery disease. Lipids Health Dis 8: 52, 2009.

32. Bekris LM, Lutz F and Yu CE: Functional analysis of $A P O E$ locus genetic variation implicates regional enhancers in the regulation of both TOMM40 and APOE. J Hum Genet 57: 18-25, 2012

33. Bennet AM, Di Angelantonio E, Ye Z, Wensley F, Dahlin A, Ahlbom A, Keavney B, Collins R, Wiman B, de Faire U, et al: Association of apolipoprotein $\mathrm{E}$ genotypes with lipid levels and coronary risk. JAMA 298: 1300-1311, 2007.

34. Bagyinszky E, Youn YC, An SS and Kim S: The genetics of Alzheimer's disease. Clin Interv Aging 9: 535-551, 2014.

35. Khan TA, Shah T, Prieto D, Zhang W, Price J, Fowkes GR, Cooper J, Talmud PJ, Humphries SE, Sundstrom J, et al: Apolipoprotein E genotype, cardiovascular biomarkers and risk of stroke: Systematic review and meta-analysis of 14,015 stroke cases and pooled analysis of primary biomarker data from up to 60,883 individuals. Int J Epidemiol 42: 475-492, 2013.

36. Bleasby K, Castle JC, Roberts CJ, Cheng C, Bailey WJ, Sina JF, Kulkarni AV, Hafey MJ, Evers R, Johnson JM, et al: Expression profiles of 50 xenobiotic transporter genes in humans and pre-clinical species: A resource for investigations into drug disposition. Xenobiotica 36: 963-988, 2006.
37. Mitsuyama $\mathrm{H}$ and May JM: Uptake and antioxidant effects of ergothioneine in human erythrocytes. Clin Sci (Lond) 97: 407-411, 1999.

38. Aruoma OI, Spencer JP and Mahmood N: Protection against oxidative damage and cell death by the natural antioxidant ergothioneine. Food Chem Toxicol 37: 1043-1053, 1999.

39. Sakrak O, Kerem M, Bedirli A, Pasaoglu H, Akyurek N, Ofluoglu E and Gültekin FA: Ergothioneine modulates proinflammatory cytokines and heat shock protein 70 in mesenteric ischemia and reperfusion injury. J Surg Res 144: 36-42, 2008.

40. Martin KR: The bioactive agent ergothioneine, a key component of dietary mushrooms, inhibits monocyte binding to endothelial cells characteristic of early cardiovascular disease. J Med Food 13: 1340-1346, 2010.

41. Akanmu D, Cecchini R, Aruoma OI and Halliwell B: The antioxidant action of ergothioneine. Arch Biochem Biophys 288: 10-16, 1991.

42. Cheah IK and Halliwell B: Ergothioneine; antioxidant potential, physiological function and role in disease. Biochim Biophys Acta 1822: 784-793, 2012.

43. Peltekova VD, Wintle RF, Rubin LA, Amos CI, Huang Q, Gu X, Newman B, Van Oene M, Cescon D, Greenberg G, et al: Functional variants of OCTN cation transporter genes are associated with Crohn disease. Nat Genet 36: 471-475, 2004.

44. Waller S, Tremelling M, Bredin F, Godfrey L, Howson J and Parkes M: Evidence for association of OCTN genes and IBD5 with ulcerative colitis. Gut 55: 809-814, 2006.

45. Tokuhiro S, Yamada R, Chang X, Suzuki A, Kochi Y, Sawada T, Suzuki M, Nagasaki M, Ohtsuki M, Ono M, et al: An intronic SNP in a RUNX1 binding site of SLC22A4, encoding an organic cation transporter, is associated with rheumatoid arthritis. Nat Genet 35: 341-348, 2003.

46. Santiago JL, Martínez A, de la Calle H, Fernández-Arquero M, Figueredo MA, de la Concha EG and Urcelay E: Evidence for the association of the SLC22A4 and SLC22A5 genes with type 1 diabetes: A case control study. BMC Med Genet 7: 54, 2006. 